\title{
A Educação Popular na Venezuela (a Missão Ribas sob a Presidência de Hugo Chávez)
}

\author{
Alzira Lobo de Arruda Campos* \\ Maria Auxiliadora Fontana Baseio** \\ Deise da Rosa Oliveira ${ }^{* * *}$
}

\section{Resumo}

O significado de "educação popular", tornado central nas políticas dos estados ocidentais no século XIX, é analisado no exemplo venezuelano, como um dos elementos principais do regime bolivarianista de Hugo Chávez, que propunha democratizar o acesso de toda a população ao sistema de ensino, por meio das chamadas "Missões Bolivarianas", das quais selecionamos a "Missão Ribas". O objetivo principal é o de contribuir para o conhecimento das relações da "educação popular" com a práxis de uma campanha de forte impacto, tanto na realidade objetiva da sociedade, quanto no subjetivismo ideológico da fidelidade aos princípios tidos como fundamentos da educação bolivariana. O espaço geográfico é o da Venezuela, em geral, e o de Caicara del Orinoco, em particular, uma cidade do interior venezuelano, na qual observamos a ação direta da política educativa bolivariana, efetivada em salas de aula, junto a professores e alunos. Palavras-chave: Educação Popular na Venezuela; Bolivarianismo; Hugo Chávez; Missão Ribas em Caicara del Orinoco.

\footnotetext{
* Mestra e doutora em História (USP); Livre-docente em Metodologia da História (UNESP); docente do Programa Interdisciplinar em Ciências Humanas, nível Mestrado (UNISA). loboarruda@hotmail.com

** Pós-doutora em Letras na Universidade do Minho; Mestre e Doutora em Estudos Comparados de Literaturas de Língua Portuguesa (USP); docente do Programa Interdisciplinar em Ciências Humanas, nível Mestrado (UNISA), e da Faculdade Rudolf Steiner.

*** Mestranda do Programa Interdisciplinar em Ciências Humanas, nível Mestrado (UNISA).
} 


\section{Popular Education In Venezuela (Riba's Mission Under Hugo Chavez's Presidency)}

\section{Abstract}

The meaning of "popular education", having become central in the politics of ocidental states in the 19th century, is analyzed in the venezuelan example as one of the main elements in hugo chávez's bolivarianist regimen, which aimed to democratize the access of the entire population to the education system, through the so called "bolivarian missions", of which we selected "ribas mission". the main goal is the contribution to the knowledge of the relations of the "popular education" with the praxis of a strongly impactful campaign, such as in the society's objective reality, as in the ideological subjectivism of the fidelity to the principles had as pillars of the bolivarian education. the geographical space is venezuela's, in general, and caicara del orinoco's, in particular, a venezuelan countryside city, in which we observed the direct action of the bolivarian educational politics, activated in classrooms, along with teachers and students.

Keywords: popular education in venezuela; bolivarianism; hugo chávez; ribas mission in caicara del orinoco.

\section{Educación popular en Venezuela (Misión de Riba bajo la presidencia de Hugo Chávez)}

\section{Resumen}

El significado de "educación popular", habiendo cobrado protagonismo en la política de los estados ocultos en el siglo XIX, se analiza en el ejemplo venezolano como uno de los principales elementos del régimen bolivariano de Hugo Chávez, que pretendía democratizar el acceso de toda la población al sistema educativo a través de las denominadas "Misiones Bolivarianas", de las cuales seleccionamos "Misión Ribas". El objetivo principal es el aporte al conocimiento de las relaciones de la "educación popular" con la praxis de una campaña fuertemente impactante, tanto en la realidad objetiva de la sociedad, como en el subjetivismo ideológico de la fidelidad a los principios que tuvieron como pilares de la educación bolivariana. El espacio geográfico es el de Venezuela, en general, y de Caicara del Orinoco, en particular, una ciudad rural venezolana, en la que observamos la acción directa de la política educativa bolivariana, activada en las clases, junto a docentes y alumnos.

Palabras clave: Educación popular en Venezuela; Bolivarianismo; Hugo Chavez; Misión Ribas en Caicara del Orinoco. 


\section{Introdução}

A partir do século XIX, e como consequência direta da Revolução Industrial, a educação popular erigiu-se como a chave mestra para o desenvolvimento social. Em primeiro lugar, tratava-se de assegurar operários capazes de operar máquinas, entendendo manuais de instrução e as regras disciplinares das fábricas. Depois, cidadãos conscientes, atuantes e motivados na luta por uma sociedade mais justa, ou para a manipulação da massa, muitas vezes moldada para atender a interesses sócio-político-econômico dominantes.

Os pressupostos acima encontram respaldo nas mais diversas áreas do conhecimento e em inúmeros autores que se dedicam ao estudo das relações entre a popularização da educação e a organização da sociedade. Esses conceitos, de início baseados em Platão, Aristóteles, Rousseau, obtiveram a contribuição do marxismo clássico, consolidado em Karl Marx e Friedrich Engels, e em marxistas contemporâneos, como Theodor Adorno e Paulo Freire. Como contrapartida aos modelos positivistas e socialistas em curso, governos preocupados com o bem-estar das camadas mais humildes da sociedade adotaram modelos marxistas, que visavam à tomada de consciência da população, em estados que se filiaram ao estilo soviético.

O caso clássico, na América Latina, foi o de Cuba, que conseguiu zerar o analfabetismo no país e conceder acesso amplo ao ensino universitário a todos os cubanos. Esse exemplo foi exportado para a Venezuela, um país repleto de polêmicas e contradições, personificadas na presidência de Hugo Chávez (1999-2013) e em seu sistema educacional, que objetivava democratizar o acesso de toda a população ao ensino, por intermédio das chamadas "Missões Bolivarianas".

O projeto começou em um momento conturbado, em que Chávez carecia, com urgência, de apoio popular. O slogan "Yo Sí Puedo", importado de Cuba, foi idealizado inicialmente para o combate ao analfabetismo e, posteriormente, adaptado e levado aos outros níveis da educação de jovens e adultos. As políticas então implementadas abrangeram todo o sistema educacional, indo das 
classes de alfabetização à formação universitária e passando por um grau equivalente ao Ensino Médio brasileiro.

O método cubano eliminou o analfabetismo no território da ilha caribenha, apelando para a consciência de classe e apostando na vontade popular de ter acesso à educação formal, acesso vinculado, antes do castrismo, às elites nacionais. No bojo da emigração do sistema de educação popular cubano para a Venezuela, enfoca-se a "Missão Ribas", um ciclo de estudos imediatamente anterior à universidade. É essa missão que constitui o polo experimental da presente reflexão, estruturada em uma rede que discute "educação popular" do ponto de vista do bolivarianismo de Hugo Chávez.

Tratava-se de um combate franco contra o uso neoliberal da educação para a manutenção do poder na sociedade, em atendimento aos interesses das classes dominantes. Assim, a análise das correntes pedagógicas faz-se em paralelo com a prática da política educacional da Venezuela, com o objetivo de buscar aferir os seus graus de eficácia teórica com a fidelidade presumida com os princípios tidos como fundamentos da educação bolivariana. Como variáveis decorrentes, indaga-se como um sistema de educação de jovens e adultos, que anulou o analfabetismo da Venezuela, pôde ser implementado num país mergulhado em grave crise político-social, em sua administração interna e no tabuleiro internacional.

Nesse âmbito, visa-se a entender os resultados reais e conhecer os princípios históricos que supostamente construíram a concepção de educação de um país socialista, mas considerado como ditatorial, pela maioria das nações da América Latina e do mundo em geral.

A problemática deste artigo aponta para um modelo analítico interdisciplinar, baseado em conceitos pedagógicos e na história política da Venezuela, durante o governo de Hugo Chávez, em suas dependências ao modelo cubano e à concepção marxista de educação popular. Tal abordagem torna necessária a inserção da teoria pedagógica inscrita na expressão "educação popular" nos objetivos políticos do bolivarianismo para se utilizar do sistema educacional 
como estratégia revolucionária de Estado, sob o prisma marxista gramsciano, largamente utilizado pelo discurso venezuelano para a formação da identidade nacional e para desenvolver a consciência de classe na população.

O tenente-coronel Hugo Chávez Frías, apoiado pelo Movimento Venezuelano Revolucionário e por partidos de esquerda, conseguiu chegar à presidência com 56\% dos votos, em 1999. Logo após vencer as eleições, Chávez convocou uma Assembleia Constituinte, sem levar em conta que a mudança constitucional deveria se apoiar numa emenda, votada preliminarmente pelos deputados, autorizando a convocação de tal assembleia. Assim teve início a relação tensa entre Chávez e o Congresso, apesar de seu desejo de que houvesse uma transição pacífica em direção ao "renascimento institucional".

Nos primeiros dois anos de seu governo, a mídia procurou se aproximar de Chávez, mas logo passou a atacá-lo de forma sistemática e intensa. Após a aprovação da Constituição e até a tentativa do golpe de 2002, Chávez permaneceu na defensiva, empenhado em administrar a crise em que a Venezuela havia mergulhado desde a década de 1980, com a queda do preço do petróleo, a base fundamental de sua economia. Vale recordar que, no momento da eleição de 1998, o barril de petróleo estava cotado em cerca de dez dólares, dez vezes menos do que o seu valor no final de 2007 (NEVES, 2010, pp. 65-66).

No amplo panorama teórico acima, inclui-se o estudo das chamadas Missões Educativas Venezuelanas, como um dos pilares da chamada "educação bolivariana" para jovens e adultos. No choque entre o reacionarismo e as mudanças revolucionárias, a evolução da educação no país enfrentou visões antagônicas, vindo a criar um ambiente de turbulência, suficiente para explicar as medidas radicais adotadas por Chávez contra adversários políticos e a liberdade de imprensa.

A aprovação popular ao governo de Chávez (em torno de $70 \%$ desde 2005) foi a sua estratégia principal para lutar contra seus 
opositores. Nesse combate, a área de projetos sociais, uma das mais importantes de seu governo, tornou-se fundamental para a manutenção da alta popularidade de que gozou, durante o seu governo e mesmo após ele. Esses projetos organizavam-se em "misiones", programas dotados de objetivos e metas específicos, a serem atingidos num espaço cronológico reduzido, por meio de intervenções efetuadas nos mais diversos setores sociais, tais como, saúde, moradia e educação.

Esta última recebeu atenção especial do governo, que criou um programa para a educação em geral e para cada um dos níveis de formação previstos. No sentido de desenvolver a consciência popular sobre a importância política da educação para o desenvolvimento humano, foi criado o programa "Moral y Luces", destinado à divulgação massiva das ideias de Simón Bolívar para todo o país.

Nas estratégias seguidas por esta reflexão, com o fim de escapar a confrontos periféricos à política educacional, centralizados em Caracas, decidiu-se que a observação da Missão Ribas deveria se concentrar em Caicara del Orinoco, a partir do pressuposto de que a aplicação do sistema de ensino bolivariano provavelmente se apresentaria em caráter mais "puro" e com maior eficiência em cidades mais afastadas da capital do país, o palco principal dos embates violentos travados por milícias aguerridas, simpáticas ou contrárias a Chávez.

Isolamento dado por distâncias culturais entre a capital e interior, mas também em razão de uma topografia complexa, marcada por muitas serras, e pelo fato de a Venezuela ser cortada, praticamente de ponta a ponta, por um dos principais rios do continente. Ademais, o isolamento das cidades interioranas é agravado em decorrência de um sistema de comunicação deficitário, dotado de poucas ferrovias, rodovias ou aeroportos. Essas circunstâncias apresentam-se com uma clara efetividade na política nacional venezuelana e explicam, em grande parte, a utilização de uma observação direta, realizada nas Missões Educativas da Venezuela, em Cai- 
cara del Orinoco, proporcionada por viagens de estudo efetuadas em agosto de 2007 e nos meses de janeiro dos anos de 2008 e 2009.

A pesquisa de campo então realizada permitiu um entendimento sobre as consequências adversas de decisões político-econômicas de um governo disposto a atender aos segmentos mais humildes da população, mas que foi levado a tomar medidas que acarretaram a carência de gêneros alimentícios e demais produtos dos mercados e farmácias, fundamentalmente em regiões do interior da Venezuela. O polo empírico é formado por observações, registradas em cadernos de pesquisa de campo, e por documentos constantes do Plano Nacional de Educação Venezuelana.

\section{Educação popular e desenvolvimento humano}

A educação, em geral, é concebida por Adorno como meio essencial de formar indivíduos conscientes, para que se torne possível a prática de uma democracia efetiva. Não se trata da mera transmissão de conhecimentos, mas da produção de uma consciência verdadeira, cumprindo o dever básico dos estados democráticos, que só se podem manter como tais enquanto estiverem integrados por pessoas emancipadas (ADORNO, 1995, pp. 141-142).

A educação popular, obviamente, deve ter como ponto de partida a realidade do povo, a fim de cumprir sua missão, com o respeito necessário ao homem, visto como pessoa e não como mero instrumento de produção e reprodução social (FREIRE; NOGUEIRA, 2002, p. 45). Nessa vertente, “a atenção aguda à realidade social circunstante dos alunos é elemento balisar para a construção coletiva de uma escolarização que conduza à autonomia e à cidadania livre" (CORTELA, 2008, p. 117).

A concepção de educação popular, iniciada com o projeto da modernidade brasileira e latino-americana, ganhou novos contornos nas décadas de 1960, 1970 e 1980, quando assumiu a responsabilidade de incorporar o saber popular ao sistema pedagógico, "contribuindo para a construção, apropriação e aplicação de conhecimentos que respondam, com pertinência e eficácia, às necessida- 
des de vida rumo à participação sociocultural e política dos sujeitos envolvidos" (GUISO, 1999, p. 32).

Em termos latos, educação popular poderia ser definida como um processo de produção e assimilação de conhecimentos, direcionado às camadas populares, num sistema de ensino e aprendizagem baseado na realidade e que incentive a participação dos indivíduos na transformação social. Nessa acepção, seria o caminho inequívoco para a diminuição das desigualdades sociais, fornecendo ao indivíduo as ferramentas necessárias para transformar a própria vida e a da comunidade em que está inserido. Concepção, ademais, a implicar uma definição de escola em que os interesses da sociedade dominante não ocupem espaço e onde se formem pessoas críticas, conscientes de seus direitos, curiosas e interessadas no conhecimento e no exercício da autonomia pessoal e coletiva.

Em caminho divergente, o ensino mecanicista e a falta de acesso à educação encontram-se em diversos períodos históricos, como forma de manutenção das estruturas sociais, privilegiando a classe dominante. De qualquer forma, a educação é um meio de intervenção no mundo, que, "além do conhecimento dos conteúdos bem ou mal ensinados e/ou aprendidos implica tanto o esforço e a reprodução da ideologia dominante como o seu desmascaramento" (FREIRE, 1996, p. 98). Em outras palavras, a reflexão pode servir tanto à dominação cega como a seu oposto; portanto, precisa ser transparente, em sua finalidade humana (ADORNO, 1995, p. 161).

As diferenças sociais mergulham suas raízes na educação, uma vez que "a desigualdade, sendo quase nula no estado de natureza, obtém sua força e cresce com o desenvolvimento de nossas faculdades e os progressos do espírito humano, tornando-se finalmente estável e legítima pelo estabelecimento da propriedade e das leis" (ROUSSEAU, 2008, p. 114). Assim, a utilidade do conhecimento é altamente desigual, pois os resultados das atividades científicas não abrangem a humanidade como um todo "da mesma forma, nem com a mesma intensidade e condições de usufruto; ainda, mas não para sempre, estamos imersos em uma distribuição 
desigual e discriminatória das benesses dessa obra humana coletiva" (CORTELLA, 2008, p. 23).

Desde o começo da história do homem, é possível encontrar a separação de classes promovida e reproduzida na e pela educação. Aníbal Ponce observa, já nas obras seminais de Aristóteles e Platão, os conceitos de formação diferenciada, para que as estruturas sociais sejam mantidas, uma vez que uma sociedade fundada no trabalho escravo não poderia assegurar a cultura para todos, além de a lógica eupátrida argumentar que o rendimento da força humana era limitado. Portanto, o homem não teria como estudar e trabalhar ao mesmo tempo.

Em razão disso, organizou-se uma divisão tripartite da sociedade, cabendo o pensamento aos filósofos, a proteção aos guerreiros, e o trabalho aos escravos, responsáveis pela manutenção da estrutura social. Tratava-se, pois, da separação total entre a força física e a força mental, de longo alento histórico, uma vez que essa ordem só passou a ser questionada no século XVI, quando More e Campanella colocam pela primeira vez a questão da propriedade coletiva igualitária, na chamada pré-história do socialismo, surgida efetivamente no final do século XVIII (PONCE, 2007, p. 60).

Para Marx, não deveriam existir nem a propriedade privada nem as diferenças de classes, após estabelecida a igualdade econômica entre os indivíduos. Os princípios da educação pública socialista, ao se assentarem no determinismo social, apenas mudam o seu caráter burguês, arrancando a educação da influência da classe instalada no poder.

As teorias positivas ou socialistas influenciaram a pedagogia latino-americana, mas a visão marxista da educação popular provocou os maiores resultados no entrelaçamento de postulados teóricos a movimentos sociais, ligando radicalmente a formação e a prática docente com os interesses específicos das classes do trabalho, uma tática considerada profunda e altamente significativa para a emancipação e o desenvolvimento das repúblicas latino-americanas. 
Nesse campo, fortaleceram-se estudos debruçados sobre as relações entre os projetos nacionais e a intitulada educação libertadora de Simón Rodriguéz e José Martí, postas em contraponto às ideias de Domingo Faustino Sarmiento. O socialismo latino-americano, com foco nas propostas de José Carlos Mariátegui, e experiências que vinculam princípios de autonomia, participação e transformação social, como no exemplo de Paulo Freire, suscitaram uma produção acadêmica numerosa e de qualidade.

De modo geral, essa produção sublinha que a educação popular se encontra vinculada a movimentos, grupos e associações populares, na luta contra práticas culturais e educativas hegemonizadoras, que servem, tão somente, aos interesses da burguesia nacional e internacional. No campo propriamente epistemológico, a educação popular é vista como um processo que procura produzir um conhecimento para a liberdade e para a democracia, recusando posições autoritárias e a reprodução de uma ideologia que obedece à lógica do mercado.

Embora na América Latina os sistemas de ensino sigam o neoliberalismo, reprodutor ideológico de uma sociedade de classes desiguais em deveres e direitos, os diversos projetos de educação popular aparecem como alternativas possíveis para diminuir as extremas desigualdades e injustiças que marcam a história das nações latino-americanas (LEMES, 2010, p. 1).

\section{Educação popular e bolivarionismo}

A educação popular na América Latina forjou-se em movimentos de resistência - entre os zapatistas no México, por exemplo - e durante a constituição das novas repúblicas latinoamericanas, como em Cuba, com José Martí, e na Venezuela, com Simón Rodríguez. Também esteve presente em múltiplas experiências que atravessaram o século XX, que podem ser ilustradas pela proposta para a educação indígena, campesina e operária, de José Carlos Mariátegui, no Peru.

Dessa forma, a educação popular tem um significado político e de classe, com base em pressupostos oriundos de um processo 
de libertação, operado por meio da conscientização e luta política dos oprimidos, inerentes a processos emancipatórios. Na América Latina, embora predomine a educação neoliberal, podem ser distinguidos quatro programas diversos na concepção e linha política em matéria educativa.

O primeiro deles, representado por Simón Rodriguéz (17711854) - o mestre de Simón Bolívar (1783-1830) -, defende um sistema escolar inclusivo de pobres, negros e índios, segmentos populares que deveriam ser vistos como o núcleo mais importante da educação. Rodriguéz entendia que a educação era "uma estratégia de transformação da sociedade para criar outra" (STRECK; ADAMS; MORETTI, 2010, p.60). O segundo programa, de responsabilidade da direita conservadora, advoga um tipo de educação afastado da intervenção do Estado, por meio do qual as camadas populares possam receber uma formação inferior à oferecida às classes superiores. $\mathrm{O}$ terceiro programa, por sua vez, enraiza-se no liberalismo oitocentista, tendo como representante principal o argentino Domingo Faustino Sarmiento (1811- 1888). Ligado diretamente ao positivismo, esse programa defende uma educação comum e primária, que corresponda às necessidades de um "povo culto" para desempenhar as funções de uma "vida civilizada". Não obstante, Sarmiento acreditava que a inteligência inferior dos indígenas, negros e gaúchos constituíam obstáculos para o progresso da América Latina (PUIGGRÓS, 2014, pp. 113-119). Por fim, o quarto programa, sob o influxo do neoliberalismo de finais do século XX, defende a desestruturação e a privatização dos sistemas educativos (MORETTTI, 2014, p. 1).

As propostas educacionais, acima esquematizadas, são fundamentais para que se possa analisar a chamada "educação bolivariana", o sistema educacional implantado pelo presidente Hugo Chávez, que acreditava ser o ensino venezuelano um dos pilares principais do socialismo do "Século XXI", ligando-se, assim, às propostas anteriormente defendidas por Rodriguéz e Bolívar. Entre os motivos pelos quais os programas sociais venezuelanos tiveram 
grande destaque durante os anos Chávez, é preciso mencionar a necessidade que o novo governo tinha de sustentar e fortalecer a sua base de apoio popular, a fim "de fazer frente não só aos desafios oposicionistas, mas de levar à prática, concretamente, uma alternativa aos planos neoliberais que tanto dano têm causado aos países subdesenvolvidos" (ALMADA, 2007, p. 81).

$\mathrm{Na}$ condição de elemento integrado à política educacional, a Misión Robinson, estabelecida por Chávez, em 2003, seguia um método dialético e visava à alfabetização de jovens e adultos, fundamentada no princípio Yo Si Puedo. Amplamente apoiado numa propaganda rádio e teledifundida, esse método preconiza, em essência, que o ensino deve ir do mais simples ao mais complexo, do concreto ao abstrato, dos números às letras.

Os alfabetizadores, chamados de agentes educadores ou "facilitadores", não precisariam ter a formação docente. Uma das principais características do Yo Si Puedo repousa na tática de partir dos números, elementos conhecidos pelos alfabetizandos, para chegar às letras, desconhecidas pelos alunos. A segunda etapa do método consta de dez aulas, dedicadas à familiarização dos educandos com as letras, ao desenvolvimento da expressão oral e de habilidades psicomotoras, além da escrita dos números de zero a trinta. Em sequência, chega-se à escrita de palavras e à produção de ideias. Em 2005, apenas dois anos depois de iniciada a Misión Robinson, a Venezuela anunciou a sua vitória contra o analfabetismo, vitória reconhecida pela UNESCO (FEITOSA, 2011, p. 136).

Para essa conquista, a Venezuela contou com o apoio de profissionais cubanos, que haviam chegado ao país três anos antes, com o objetivo de ajuda humanitária prestada na situação de emergência, causada por um deslizamento de terras, que afetou gravemente dez dos estados do território nacional. Nessa situação, os cubanos se responsabilizaram, primeiramente, pelo atendimento médico nas regiões mais pobres das cidades e nos meios rurais. Mais tarde, esse auxílio se ampliou para outras áreas, dentre as quais a educação revelou-se como fundamental para combater o analfabetismo, pela 
implementação do método cubano "Sim, eu posso", em consequência do qual a Venezuela erradicou o analfabetismo dentro de suas fronteiras e foi reconhecida, pela UNESCO, como um "Território Livre do Analfabetismo”, em 28 de outubro de 2005.

No contexto latino-americano, a Venezuela tornou-se o segundo país a atingir essa meta educacional, ficando apenas atrás de Cuba. O projeto, como um todo, depende da participação de voluntários das comunidades e da aliança com as Forças Armadas, que garantem suporte físico, logístico e até humano. A integração cívico-militar bolivariana reveste-se de um enorme esforço coletivo de reflexão e auto-educação do Governo Chávez para estabelecer uma nova maneira de pensar o homem e a sociedade.

Esse processo visa à solidariedade e à justiça social, contrapondo-se ao modelo social guiado pela lógica de auferir lucros pela exploração do trabalho dos membros das classes sociais mais humildes. Nesse esquema e a partir dele, as elites venezuelanas desencadearam movimentos de reação, consubstanciados em tentativas constantes para desestabilizar o governo, utilizando-se largamente da mídia privada e de um grupo de opositores violentos e golpistas (ALMADA, 2007, p. 86).

As missões educativas apresentam-se subdivididas de acordo com os objetivos, as fases e o público que devem ser contemplados pelo programa. Nesse âmbito, a primeira fase das missões educativas, intitulada Missão Robinson I, é considerada como a operação cívico-militar mais importante da história do país, uma vez que conseguiu erradicar o analfabetismo da Venezuela, por intermédio da implementação do método cubano "Sim, eu posso", já referido. Essa missão foi lançada pelo Plano Nacional de Alfabetização, que foi assessorado por 70 pedagogos vindos de Cuba e mais de 100.000 voluntários venezuelanos, chamados de "facilitadores".

A Missão Robinson II, como a segunda fase do sistema educativo, tem por objetivo garantir o prosseguimento dos estudos aos cidadãos já alfabetizados (D’ÉLIA, 2007, p. 38). O nível subsequen- 
te, chamado de "Missão Ribas", configura o foco da observação in loco deste trabalho, como abaixo se descreve.

\section{A Missão Ribas e o método "Sim, eu posso"}

Em todas as missões, o método "Sim, eu posso" propõe-se a combater o analfabetismo em pouco tempo e com baixo custo, utilizando-se de recursos audiovisuais, a partir de um sistema flexível, adequado às necessidades dos educandos. O método foi criado pela professora cubana Leonela Relys, e se baseia em recursos técnicos, fundamentalmente vídeos, acompanhados por cartilhas idênticas às das imagens assistidas pelos alunos, na presença de facilitadores - em geral, voluntários, apenas com a formação básica concluída. Os facilitadores são treinados por supervisores, todos com formação pedagógica.

$\mathrm{Na}$ fase de alfabetização, o método consiste em ir do conhecido (os números) ao desconhecido (as letras) e contém as subfases de adestramento, de ensino da leitura e da escrita, perfazendo o total de 65 aulas, cada uma com a duração de 30 minutos. As aulas são ministradas em cinco dias da semana. Os alunos recebem uma cartilha, que combina números e letras. Na primeira etapa, as aulas transmitem informações aptas a estimular a consciência crítica dos alunos, preparando-os para promoverem transformações na sociedade. Em cada aula, são abordados temas de grande interesse popular, oriundos de necessidades mais comuns das regiões onde o projeto é aplicado, demarcando, especialmente, questões de saúde, convivência familiar e atendimento à terceira idade (CORTELLA, 2008, p. 14).

Nas fases seguintes, a metodologia adquire outros conteúdos e se torna mais complexa. O sistema cubano foi adotado por vários países: Venezuela, Haiti, Nicarágua, Nova Zelândia, Argentina, Paraguai, México e Brasil. Na Venezuela, a Missão Robinson II surgiu com a intenção de dar continuidade à formação de estudantes que participaram da Robinson I, e àqueles que, por algum motivo, abandonaram a escola até o sexto grau. A Robinson III objetiva promo- 
ver círculos de debates em leituras, mediante a atualização de temas políticos, econômicos, sociais e culturais de interesse nacional.

A Missão Ribas, criada em outubro de 2003, tem por objetivo trazer de volta aos estudos todas as pessoas que não tenham concluído a terceira etapa da educação média, promovendo a continuidade educativa dos indivíduos anteriormente beneficiados pela Missão Robinson. Até agosto de 2014, foram graduados 822.853 alunos e estão registradas 1.632.726 matrículas nesse programa (LÓPEZ

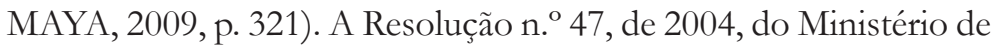
Educação e Desportes, define que o "Plano Extraordinário José Félix Ribas”, ou "Missão Ribas", "objetiva prioritariamente garantir a continuidade de estudos àqueles que não conseguiram ingressar ou terminar seus estudos desde a terceira etapa da educação básica até o nível de educação média diversificada ou profissional" (D’ELIA; CABEZAS, 2007, p. 59).

Da mesma forma que as missões anteriores, as lições da Ribas são transmitidas por videoaulas, com uma versão correspondente registrada em cartilhas e cadernos de exercícios da disciplina estudada, segundo atividades desenvolvidas em classe e sempre acompanhadas por facilitadores. A estrutura pedagógica e o conteúdo baseiam-se no "perfil republicano bolivariano" que se espera construir, por meio de uma ação formativa adequada para produzir cidadãos capazes de valorizar a si próprios e à comunidade, a fim de "viver na democracia de forma protagônica e co-responsável, nos marcos do ideário bolivariano, tendo em vista a construção de uma sociedade de boa convivência, solidária, de justiça e paz" (DOCUMENTO 1, 2004, p. 2).

O currículo abrange interrelações de áreas do conhecimento com elementos de "cidadania", em especial, os chamados "Marcos da Refundação da República": identidade, soberania, cidadania, participação, direitos humanos, novo Estado e educação ambiental. Esses pressupostos são trabalhados nos temas: Filosofia Humanista, Ideário Bolivariano (princípios de cooperação, solidariedade, convivência, bem-comum, unidade, auto- determinação e integra- 
ção), Constituição da República Bolivariana da Venezuela e linhas gerais do Plano Nacional de Desenvolvimento. Os alunos da missão Ribas são chamados de "vencedores", porque o nome da missão é uma homenagem a um militar que participou das lutas pela libertação da Venezuela e venceu uma batalha (DOCUMENTO 2, 2003, pp. 3-4).

O sistema de avaliação consiste na descrição e valoração das competências e capacidades humanas apontados por Jacques Delors para a UNESCO, em 1997: aprender a conhecer, aprender fazer, aprender a conviver e aprender a ser. Em decorrência, a avaliação do processo se dá por meio da autoavaliação e da coavaliação, realizada pelo grupo e pelos facilitadores, além da heteroavaliação, efetuada em assembleias. Nas quatro dimensões supracitadas, o processo avaliativo procura observar "a formação do ser social e solidário; o conhecimento de conteúdos conceituais e processos cognitivos; a aplicação do conhecimento em outras situações da vida e a convivência com a prática de relações de apoio mútuo e busca do bem comum" (DOCUMENTO 2, 2003, p. 52).

\section{A Missão Ribas em Caicara del Orinoco}

A cidade de Caicara del Orinoco fica na região central da Venezuela e tem 40 mil habitantes. Por meio das visitas já mencionadas, foi possível acompanhar de perto a aplicação da Missão Ribas à população local, após contatos prévios com a Unidade Educacional Manuel Manrique, facilitados por moradores da cidade, que atuaram como intermediários entre as intenções de pesquisa e os seus dados conclusivos.

Obtida a autorização, tornou-se possível acompanhar as atividades na sala de aula designada, sob a regência da professora Sandra Palma. Dessa sala, participavam seis alunos, quatro deles ainda em idade de cursar, com pequeno atraso, a escola regular, e dois que deixaram em casa seus afazeres em busca do conhecimento. Uma aluna levava para a sala de aula sua filha, de sete anos, porque não tinha com quem deixá-la. 
A duração do curso para o término do ensino médio é de dois anos, com aulas diárias, das 17 h30 às 19h30. A professora Sandra é aluna da Missão Sucre, estudante de Pedagogia aos sábados, das $7 \mathrm{~h} 00$ às $12 \mathrm{~h} 30$ e nos domingos, das $14 \mathrm{~h} 00$ às $17 \mathrm{~h} 30$. Sandra, assim como todos os alunos matriculados no curso de Formação de Professores da Missão Sucre, que tem a duração de cinco anos, precisa trabalhar na Missão Ribas, perfazendo uma espécie de estágio, que tenta aliar a necessidade da prática dos formandos à possibilidade de levar conhecimento às mais longínquas regiões do país, dando continuidade e expandindo o projeto das Missões.

Durante as aulas, a professora Sandra contou com um videocassete, praticamente o único recurso disponível em sua sala. As aulas principiavam com a chamada e a informação sobre a matéria do dia, enquanto os alunos abriam seus cadernos, divididos por disciplinas. Ligava-se, então, o videocassete e se iniciava a apresentação gravada de itens de disciplinas variadas (história, geografia universal, geografia venezuelana, química e matemática, por exemplo).

A cada dia eram ministradas duas aulas, com um pequeno intervalo entre elas, ocasião em que os alunos iam ao banheiro e bebiam água. A rotina escolar, substancialmente, limitava-se à observação das videoaulas do dia, em cuja tela apresentava-se uma professora falando sobre os temas programados, com o auxílio de ilustrações e resumos em tópicos, que os alunos copiavam durante ou logo após a exibição do vídeo.

$\mathrm{Na}$ dinâmica das aulas, não se notou a existência de perguntas: os alunos apenas mantinham sua atenção presa à aula televisiva e se esforçavam por copiar os textos registrados. A professora Sandra, no final da aula, limitava-se a anunciar a disciplina a ser exibida após o intervalo. De volta à sala, os cadernos eram abertos em outra divisão e mais um vídeo, com a duração de 45 minutos, era apresentado, definindo uma rotina consecutiva e recorrente, até o término da aula. Quanto aos conteúdos, principalmente os de História, o acento é dado ao tema da exploração das camadas mais pobres pelas classes dominantes. 
Nesse discurso, imagens do Ancien Régime europeu se sobrepunham dialeticamente, como no caso da exposição figurativa de castelos suntuosos, a serem observados em contraposição à simplicidade das moradas de camponeses ou à miséria dos servos da gleba. À guisa de exemplo, abaixo se inscreve a tradução dos conteúdos, conforme os esquemas registrados no vídeo e copiados pelos alunos, de uma das aulas observadas em Caicara del Orinoco, em janeiro de 2009.

Na aula de História, "lição n. ' 12", sobre o Absolutismo Europeu, no século XVIII, os principais pontos destacados referiamse a definições sobre o sistema monárquico como uma forma de transição entre o feudalismo e o capitalismo, na qual o Estado era o Rei, cujos poderes eram de origem divina. $\mathrm{Na}$ segunda tela, foi exposta uma fotografia de Luís XIV, devidamente referenciada. O "Absolutismo Francês", vindo logo após, é definido pelas palavras-chave, reproduzidas em sua literalidade: Luís XIV, poder ilimitado, muitos poderes, decidia a guerra e a paz, dispunha de todos os recursos do Estado, era a fonte da lei e da justiça.

O tema seguinte, a política mercantilista de Luís XIV, está resumida nestes tópicos: setores pobres, indústrias para o comércio exterior e interior, enriquecimento da coroa, criação de uma frota mercante e grandes companhias, impostos diretos sobre o consumo da população. Sobre estruturas feudais, discriminaram-se: aristocracia feudal, nobreza arruinada e corrompida e grandes luxos, alta burguesia financeira e comercial, camponeses sofridos, técnicas atrasadas, aumento da população urbana. O último assunto tratado cuidou da crise no final do reinado de Luís XIV, exposta segundo os itens: baixos salários, custos de modernização do exército, guerras, deboche da corte, altos impostos para os camponeses, população miserável.

Para encerrar a videoaula, foram exibidas duas fotos do palácio de Versailles, como contraste com os itens anteriormente estudados. A legenda dessas fotos trazia a frase: "o palácio e os jardins de Versailles, nos arredores de Paris, são famosos por seu luxo e 
beleza". Todos os textos e ilustrações foram acompanhadas de explicações, realizadas pela professora "virtual" Adalgiz Hernandes. Em alguns momentos, não se ouve a sua voz, substituída por uma música de fundo. Era o momento apropriado para os alunos copiarem as informações contidas em esquemas das aulas respectivas.

Ao final do terceiro dia, tornou-se possível fotografar e conversar com a professora e os alunos. Estes, em sua totalidade, garantiram estar muito satisfeitos com o curso, principalmente porque não tiveram como frequentar o ensino regular e não conseguiriam terminar seus estudos, se não fosse a Missão Ribas. Eles também agradeceram à professora Sandra, por co mparecer todos os dias à Escola Manuel Henrique e por funcionar como uma ponte entre a vontade dos alunos e a oportunidade que teriam de concluir o curso.

A professora Sandra Palma, por sua vez, prestou informações sobre o funcionamento, tanto da Missão Ribas, em que atua como docente, quanto da Missão Sucre, onde estuda, manifestando sempre um entusiasmo exaltado pela aplicação das Missões à realidade da Venezuela, além de não ver defeitos nas Missões das quais participa, ressaltando que os alunos aprendem, além de terem a oportunidade de usufruirem de benefícios oferecidos pelas missões para a população carente.

A respeito da avaliação do aproveitamento dos alunos, Sandra explicou que ela faz a chamada, para observar a frequência, marca quem faz anotações, quem copia e quem presta atenção à aula. Com essas informações, elabora relatórios individuais sobre os alunos. Ao final dos dois anos de curso, os estudantes, com bom aproveitamento, recebem um diploma equivalente ao Ensino Médio do Brasil ${ }^{1}$.

As informações constam de três cadernos em que estão anotadas as observações diretas auferidas em viagens de estudo, realizadas no período de 2007 2009, integrantes no Arquivo Particular das Autoras. 


\section{Considerações Finais}

Uma frase escrita na tela da TV chama a atenção no começo de cada videoaula da Missão Ribas, observada na cidade de Caicara del Orinoco: "Ser culto é o único modo de ser livre". De fato, pelo menos na ideologia, a intenção da missão corresponde aos ideais socialistas de educação, em especial à concepção socialista de educação universal, pregada por Marx e Engels e ao conceito de educação para a autonomia, valorizada principalmente em Freire.

Na prática, o que se observa é que as intenções que o Estado venezuelano avoca como suas tropeçam nas crises econômicas contínuas e na oposição sistemática da mídia e de nações estrangeiras, filiadas ao neoliberalismo norte-americano. Ideias e conceitos presentes no discurso chavista, com continuidade em seu sucessor, Nicolás Maduro, estão distantes de uma aplicação fidedigna na "Missão Ribas", observada na realidade de Caicara del Orinoco. As cartilhas, por exemplo, que deveriam acompanhar as lições do vídeo, como se encontra idealizado no método Yo Sí Puedo, inexistem nessa região. $\mathrm{O}$ único material recebido pelos alunos consiste de um caderno com divisões, destinadas às cópias de esquemas e resumos apresentados nas videoaulas.

O fato, entretanto, é que, em toda a Venezuela, desde a Revolução Bolivariana, a matrícula regular nas escolas cresceu em mais de seis milhões de crianças, um aumento de $23 \%$. Uma das conclusões a que se pode chegar é que os pais que estudam incentivam seus filhos a frequentar as aulas. Aí se situa, talvez, o maior legado da educação popular na Venezuela.

Também é certo que a expansão das missões e a ausência de fiscalização e de investimento geram sérios problemas de infraestrutura e de garantia de qualidade. Opositores ao Governo, nos poucos espaços em que a imprensa ainda não foi controlada por Chávez/Maduro, chegam a apontar a corrupção como o motivo dos problemas e como o desafio para se seguir adiante com o modelo socialista. 
Não se pode perder de vista que as missões bolivarianas foram criadas, segundo Chávez, para consolidar a democracia participativa, por meio da eliminação da exclusão social, e que ele fez isso por convicção, mas também por necessidade de apoio popular para evitar novas tentativas de golpe para afastá-lo do poder. Na prática, o que pôde ser observado na Missão Ribas, de Caicara del Orinoco, é que a população acredita, sem opinião contrária ou qualquer questionamento, que as missões educativas agem no sentido de tentar oferecer igualdade de oportunidades a todos, reproduzindo a concepção da educação popular, democrática e autônoma dos primeiros tempos da revolução.

O que também preocupa, para além da qualidade do ensino, é a forma como os seus resultados são divulgados. O Ministro do Poder Popular para a Educação, Héctor Navarro, por exemplo, declarou recentemente à imprensa internacional que os números referentes ao crescimento escolar do país mostram "uma sociedade desenvolvida com níveis culturais adequados, que se aproximam cada vez mais dos níveis dos países europeus". Vimos, porém, que a qualidade educacional, pelo menos a da Missão Ribas, em Caicara del Orinoco, não permite tal comparação.

A estrutura precária para o desenvolvimento do ensino, o caráter voluntário dos facilitadores, que não recebem salários, as videoaulas desinteressantes, as estratégias pedagógicas deficientes, a ausência física do professor em sala de aula, levam à conclusão de que, apesar de ganhos inquestionáveis, ainda resta muito caminho a percorrer para que as Missões Educativas Venezuelanas possam fornecer aos alunos ferramentas que garantam a igualdade econômica, política e social ao país. Infelizmente, essa decisão não pertence apenas aos venezuelanos, que se encontram relativamente isolados no cenário internacional. Entretanto, os primeiros passos foram dados, a partir do momento em que as Missões Bolivarianas incentivaram a crença de que a construção de uma sociedade mais justa é tributária da educação popular. 


\section{Referências}

ADORNO, Theodor W. Educação e Emancipação. Rio de Janeiro: Paz e Terra, 1995.

ALMADA, Izaías. Venezuela, o povo e as Forças Armadas. São Paulo: Caros Amigos, 2007.

CORTELLA, Mario Sergio. A escola e o conhecimento: fundamentos epistemológicos e políticos. São Paulo: Cortez, 2008.

D'ELIA, Yolanda. Las Misiones Sociales en Venezuela. Caracas: ILDIS, 2008. Colección Temas de Hoy. Caracas: MinCI, 2007.

D’ELIA, Yolanda; CABEZAS, Luis Francisco. Las Misiones Bolivarianas. Colección Temas de Hoy. Caracas: MinCI, 2007.

DOCUMENTO 1. Plano Nacional de Educação Venezuelana. Missiones Bolivarianas. Caracas: Ministério da Comunicación e Información. Caracas: 2004.

DOCUMENTO 2. Plano Nacional de Educação Venezuelana. La Formación de Educadores y Educadores. Caracas: Ministério da Comunicación e Información. Caracas: 2003.

FEITOSA, Nabupolasar Alves. A Educação Bolivariana. Revista: ponto-e-vírgula, v. 10: 134-149, 2011.

FREIRE, Paulo. Pedagogia da Autonomia: saberes necessários à prática educativa. São Paulo: Paz e Terra, 1996.

FREIRE, Paulo; NOGUEIRA, Adriano. Que fazer? Teoria e prática em educação. São Paulo: Paz e Terra, 2002.

GUISO, Alfredo. Práctica Social Popular y La educación popular. Universidade de Ijuí, Ano 6, n. ${ }^{\circ}$ 23, 1999.

LEMES, Marilene Alves. Didática e Prática de Ensino na relação com a Sociedade. A Educação Bolivariana. Nova Hamburgo: EdUECE, 2010, Livro 3.

LÓPEZ MAYA, Margarita. Luta hegemônica na Venezuela. A crise do puntofijismo e aascensão de Hugo Chávez. Caracas: Alfadil, 2005. Edição em português atualizada comacréscimo do cap. 16, sobre a conjuntura política até 2009.

MORETTTI, Cheron Zanini. Didática e Prática de Ensino na relação com a Sociedade. A Educação Bolivariana. São Leopoldo: EdUECE - Livro 3, 2014. 
NEVES, Rômulo Figueira. Cultura política e elementos de análise da política venezuelan $a$. Brasília: FUNAG, 2010.

PONCE, Aníbal. Educação e Luta de classes. São Paulo: Cortez, 2007.

PUIGGRÓS, Adriana. La disputa por la educación en América Latina. Hegemonía y alternativas. In: SOLLANO, Marcela Gómez; ZASLAV, Martha Corenstein. Reconfiguracíon de lo educativo en América Latina. Experiências pedagógicas alternativas. México: UNAM, 2014.

ROUSSEAU, Jean-Jacques. Discurso sobre a origem da desigualdade entre os homens. Porto Alegre: L\&PM, 2008. 